\section{Strategic relationship management and civic information in an}

\section{activist organization}

Wiebke Reile

This study examines the organizational practices of CODEPINK: Women for Peace, a social activist organization, between January 1 and October 1, 2018 to understand the organization's strategic data-driven practices during activist campaigns. The results provide important insights into the mechanisms a digital-grassroots organization takes to spread civic information to users for political participation. In a series of semi-structured interviews, analyzed with content-analysis, respondents indicated organizational practices that included the use of a non-partisan political customer relationship management (CRM) platform, social matching, and interestbased targeted emailing. CODEPINK uses these tools to help facilitate support for fundraising, direct marketing and organizing campaigns. Understanding how socia movement organizations use media innovations to support their action repertoires provides a better framework for understanding modern-day activist practices.
Keywords

social media activism; CRM, civic information, social networking sites, collective action, media innovation

\section{INTRODUCTION}

The practices of online social activist organizations have changed the way civil society interacts with civic information and political movements. The very nature of social movement organizations is changing and becoming less bureaucratized and thereby easier for individuals to engage in political activism and use information and communication technologies (ICT's) (Castells, 2015). Technological developments within ICT's have allowed social movement organizations (SMOs) to develop action repertories that utilize new media innovations to create social change. This study addresses the need to understand the practice of modern-day activists within this new digital landscape and the relationship they have to new media technologies. Currently, within the United States there is an increase in political and social activism, occurring alongside the nation's discontent with governmental policies and the Trump administration's discrimination against the marginalized middle and lower classes (Jordan \& Clement, 2018). Political activism is one of the hallmarks of American democracy, however there are still relatively small measures of success within protest history that have resulted in actual change in policy (Brancati \& Lucardi, 2018). Online social movements such as \#metoo and \#blacklivesmatter have spurred large politically charged demonstrations within the United States, however they have not brought about mass social change. The sheer size of a protest in modern-day America is not an indicator that change will occur as a result. Similarly, the amount of online digital discontent on social networking sites is also not a strong indicator that actual policy change could take place (Tufecki, 
2017). Despite this challenge, social networking sites have been the central medium to facilitate the civic engagement of individuals and are significant in overcoming common problems of activism such as free-riders, coordination, and organization (Bimber, Flanagin, and Stohl, 2012; Highfield, 2016).

With the use of customer management systems (CRMs) by political candidates and wide-spread mis-information tactics in today's media, American citizens are experiencing mistrust in their political structures and civic information systems (Rainie \& Perrin, 2019). Due to the saturation of political and civic information available online, contemporary social movement organizations experience challenges retaining the attention of members, building consistent relationships with members, and maintaining participation in activism without reaching activist burnout (Chen \& Gorski, 2015). Using CRMs have allowed activist organizations to become digital centers for distributing civic information and organizing their membership connections more effectively (Reile, 2019). Moreover, with the expansion of these digital technologies they are changing the trajectories and outcomes of social movements, while enhancing digital coordination to facilitate organized collective action (Tufecki, 2017).

This research seeks to address the relationship between media innovation and social change by ex- amining the digital media practices of CODEPINK: Women for Peace. In the following section I will explain how this organization can provide insight for this study. Specifically, examining how more data driven repertoires are utilized by CODEPINK to garner support for activist campaigns.

\section{CODEPINK: WOMEN FOR PEACE}

CODEPINK, founded in the Fall of 2002, is a women-led grassroots organization that is "fighting to end U.S wars and militarism, support peace, and human rights initiatives, and redirect our tax dollars into healthcare, education, green jobs and other life-affirming programing" (CODEPINK, 2019). The organization does not only serve women, but is nonbinary, gender non-confirming, and welcomes men.

CODEPINK was started by three women in 2002, when they set up a four-month vigil with 100 other women in front of the White House to stand up for peace against the U.S.-led war in Afghanistan. By the end of the fourth month of protest the women had 10,000 other women join their efforts. Since 2002, the organization has grown to become a worldwide network that continues to fight for social justice and has become infamous for targeting warmongers. Examples of their activist work include: getting arrested with Jane Fonda to rally against climate change, protesting Condoleezza Rice at a Foreign Relations
Committee hearing, disrupting the Kavanaugh Senate hearing, and protesting to stop Airbnb to allow renters in occupied areas (CODEPINK, 2019). They are particularly well-versed in building large audiences using social networking sites, which they manage using a CRM called NationBuilder. CODEPINK's use of NationBuilder has been rather controversial, however the organization needed a way to manage digital communications to reach out to individuals as traditional grassroots practices are inefficient in today's digital landscape. The CRM is controversial due to its aggregation of public user-behavior to influence political campaigns. On the platform the organization treats users as citizens and not as customers, because they seek to be relational rather than transactional when communicating with members. CODEPINK is an example of a digital grassroots organization, which has integrated a digital strategy to expedite fundamental organizing practices, like member management, that are standard for modern-day organizations (Reile, 2019).

Digital civic engagement actions on behalf of CODEPINK range from commenting on a social networking site, signing a petition, emailing a political figure, or joining a protest. The organization utilizes multiple channels in order to gain enough traction to organize an event or action (Reile, 2019). To join CODEPINK, there is a low-level threshold of signing 
up on the website, entering your email, or following a social networking page. This allows for citizens to have easy access to information about activist campaigns and engage on behalf of the organization.

\section{THEORETICAL FRAMEWORK AND RELATED}

LITERATURE

For the purpose of this research the following section is organized as follows: I will review the theoretical framework and examine the existing literature related to civic information, customer relationship management systems, and social movement organizations. This is followed by an overview of the methodology and approach to analysis and a presentation of the findings.

Theoretical Framework

Social movement theory is rooted in social science research that seeks to explain the social, political, and cultural implications of the mobilization of individuals. Bimber, Flanagin, and Stohl (2012) re-conceptualized social movement research within the context of modern-day activist organizations. They focused on the assumption that the decision to participate in a social movement is not purely an individual one and that the main focus of study should be on the communication and structural problems of coordinating collective action. For the purpose of this study, I employ
Bimber, Flanagin, and Stohl's (2012) assumptions to analyse the data-driven communication practices of CODEPINK. In the following sections I will review related research focusing on civic information, political CRMs, and social movement organizations. This literature was reviewed because of its focus on structural, social, and communication problems that challenge modern-day activist organizations.

Civic Information

Civic information is the flow of information, facts, opinions, and ideas that help individuals create informed decisions about political and public concerns where they identify opportunities for action (Wells, 2017). Modern-day civic engagement is associational and heavily tied to social capital (Shores, Porath, Jefferson, 2019). Mistrust of information, in particular, has increased substantially, with the intensification of fake news and the "proliferation of doctored narratives that are spread by humans and bots" (Anderson \& Rainie, p.3, 2017). According to Pew Research, 64\% of adults think that fake news is causing a problem of confusion and that they have engaged with and shared content that was fake unintentionally (Anderson \& Rainie, 2017). Political polarization, distrust in government officials, and media fragmentation are fostering an environment that is making it hard for citizens to draw the line between information and misinformation. Alawadhi (2019) in his research found that individuals trust in technology, but do not have trust in government and civic information due to a lack of perceived usefulness by citizens. Building social capital with members therefore requires the provision of reliable civic information and the development of relationships through engagement.

Karp (2012) found that organizations can play a key role in generating media interest around particular political issues at pivotal times. Wells (2017) categorizes civic information as having two different paradigms: one rooted in the social and one in new media technologies. The social paradigm involves ways in which basic foundations of social organizations have shifted in the west; the technological paradigm involves ways in which individuals interweave civic information with digital communication technologies. Furthermore, these social and technological changes have shifted the meaning and use of civic information within socio-political organizations involving young adults. Wells (2017) attributes these socio-technical mechanisms to globalization, and more specifically to the concept of the "networked society" as described by Manuel Castells (2012). The global connectedness of individuals changes the space and time of information and how those structures are organized. By consequence, the salience of individual concerns has declined, and social and political insti- 
tutions have lost a degree of influence (Wells, 2017). By contrast, garnering support from users who are already interested in civic information via previous email engagements is aiding the public in identifying topics for action (Wells, 2017).

The acceleration in the creation and distribution of information across digital channels in the modern era has fused local and global activism. By consequence, modern institutions are unable to resolve global challenges and issues as quickly as they arise. Thus, according to Beck (1999) citizens are left on their own as participants in a global society where social institutions are unable to develop relationships with them. Social organizations are increasingly being recognized as groups instead of distal organizations that individuals could depend on to affect change in political regulations and rights. This new level of perceived connection and interactivity has a direct impact on the choices citizens make to engage in organizations and their "faith in them being able to have influence" (Wells, 2017, p. 35). Moreover, challenges arise with retaining members' interest in protesting on behalf of social movement organizations. Therefore, it is necessary to explore how relationships with members of modern social movement organizations are developed, with particular regard to the role of data driven action repertoires.

Bimber, Flanagin, and Stohl (2012) in their re- search on three different organizations found that civic experience and media use are influenced by the ubiquitous nature of the tools that are available for communication practices. With citizens having many outlets for civic information, individuals have gained many opportunities to engage. This has been hard for organizations to overcome (Bimber, Flanagin, and Stohl, 2012).

Political CRMs: Customer Relationship Management Tools

Customer relationship management tools, formerly known as contact management, developed early in the business and private sectors to provide consistent customer insights based on interactions. Their purpose was to predict customer needs, products, and future purchases (Al-Khouri, 2012). CRMs are generally believed to be traced back to when vendors were able to build interpersonal relationships (Pan, Tan, \& Lim, 2006). The concept was based on the idea that businesses could create better customer loyalty and develop stronger relationships (Al-Khouri, 2012). More importantly, organizations could control communication channels, processes and politics, and become customer- rather than product-centric (Das \& Mishra, 2019). Kotler (1997) points out that CRMs firstly involve a deep analysis of consumer behavior, secondly based on social interactions, businesses fo- cus their strategies on relational marketing. A common argument suggests that CRMs were created as a decision-making platform for managers to aggressively capitalize on every single customer's potential (Pan, Tan, \& Lim, 2006).

Part of the practice of utilizing a CRM is that users provide information about themselves to a website or social network. Newlands, Lutz, Fieseler (2019) found that, "this data, handed over by the user to create such trust, covers basic aspects such as profile information, photographic identification, identification verification documents, and financial information" (p.99). Furthermore, they found that there is little certainty about the outcomes of user data that is being collected by platforms (Newlands, Lutz, Fieseler, 2019). Deighton and Johnson noted that nearly $71 \%$ of online user data is being harnessed by corporations or platforms to refine business practices (Johnson \& Deighton, 2013).

CRMs have been developed and used by many different business sectors, but are now also used by governments to develop relationships with citizens. Alawadhi (2019) found that there are many factors that impact trust with the adoption of e-government services, including how individuals are impacted by the civic information they receive. According to $\mathrm{Al}-\mathrm{Khou}-$ ri (2012) in his research with the British government, CRMs were being used by the public sector, especially 
by local governments to try and understand how they could best disseminate public services. The British government shifted away from Weberian practices of hierarchical bureaucracy, and started seeing citizens as human clients of government e-programs (AlKhouri, 2012). These programs allowed governments and politicians to introduce opportunities for online interaction and political participation (Alawadhi, 2019). According to Reddick (2010), citizens believe they need multiple different channels to get in contact with government services and officials. Moreover, Reddick and Anthopoulos (2014) found that besides traditional channels, citizens need different methods and communication technologies such as digital media, text messages, and social media. Furthermore, the choice of channel is dependent on the type of services or information the citizen needs to resolve their problems (Reddick \& Anthopoulos, 2014). According to Alawadhi (2019), as citizens have more opportunities to engage with e-government, they are perceiving more trust and transparency in political engagement.

The need to have a better connection to individuals and manage relationships has also developed in the political sector in elections and activism. Political campaigns are increasingly using customer relationship management tools to connect voters or citizens with civic information. Similarly, activists are utilizing CRMs to spread civic information and inspire in- dividuals to participate politically.

The use of political CRMs in the United States has implications for privacy protection. These issues were first noted by the British Newspaper The Guardian, when it was found that Republican politicians were misusing personal data to further political agendas (Davies, 2015). Understanding how the CRM is changing the relationship between organizations and members provides an understanding into an organization's data-driven action repertoires. With this change in practice the business and the political sector are changing how activist organizations relate to citizens. They are also developing a streamlined process for targeting social justice issues.

Social Movement Activist Organizations

The term social movement organization was introduced into social movement research in the mid1960's by Zald and Ash (1966). A social movement organization, abbreviated as SMO, is a formal activist organization that has a set shared of goals, which are coordinated through the organization and its members (Zald \& Ash, 1966). The goal of a social movement organization is to accomplish collective action, which according to Snow and Cress (2000), is in its most basic form two or more individuals coming together to protest. Some contemporary organizations, like moveon.org, do not rely on identified leaders or prescribed roles, as these are not considered central to the organization to accomplish collective action. This has resulted in computer mediated memberships, rather than the traditional formal memberships, which are hard for organizations to garner in today's media landscape (Bimber, Flanagin, and Stohl, 2012). With social movements such as Black Lives Matter and the Women's March, the importance of formal organizations has declined, while the importance of social ties between community members and engagement in social networks has increased bonds of reciprocity (Rosenblum, 2018).

According to Zald and Ash (1966), SMOs are different from bureaucratic organizations because they wish to restructure society and attempt to change social injustices. Furthermore, SMOs have purposive incentives, which makes keeping memberships difficult because the goals of an organization must be more important than the societal demands and responsibilities of everyday life if a member is to remain interested over a long period of time (Zald \& Ash, 1966). One important aspect is that social movements have an "ebb and flow" of interest from society at large and its members (Zald \& Ash, pg. 330, 1966). The relationship between the members of the organization and the cause is constantly evolving with support and changes in terms of cooperation and involvement in organizational successes and failures 
(Zald \& Ash, 1966).

As complex membership institutions, these organizations have sets of issues that drive their collective action. SMOs are seen as the central actors in coordinating and mobilizing sustained support for any social movement community pursuing activism (Jenkins, 1983; Zald \& Ash, 1966). Spreading civic information, coordinating support, and mobilizing, are known as action repertories. These provide supporters with opportunities to act in a political action. In this digital age, action repertories can refer to online and offline actions that create collective action (Selander \& Jarvenpaa, 2016; Milan, 2013). Due to the digital environment, traditional notions of resources being a barrier for activism are no longer as relevant. However, having enough resources to maintain an online presence is now a core focus (Dumitrica \& Felt, 2018). Due to social networking sites and ICTs, organizations like CODEPINK require little to no resources for citizens to join micro-mobilizations on a regular basis. However, the same challenges that have always plagued social movement organizations continue including: maintaining interest, engagement, and creating a sense of belonging amongst members.

Putnam's (2000) work focused on the organizational and found that SMOs benefit from building social capital amongst members. Johnston et al. (2011) found that there is an increase of social capital within a community when it commits to joining collective action. Furthermore, heavier social networking site (SNS) users have been found to participate more in organizations and be more in touch with friends and relatives (Wellman, Quan-Hasse, Witte, \& Hampton, 2001). However, this formation of social trust and reciprocity can occur in a variety of different contexts online and offline outside of formal organizations. Understanding who is the primary benefactor of an organization's membership formations and civic engagement can help with understanding the associations people are building. The power in achieving collective action through social capital is not about the interpersonal connections that are made, but about individuals posting their private opinions and preferences on mass public issues.

As outlined in this literature review, there is a need to understand how using a CRM can change how SMOs relate to their members and communicate civic information. The following research question was formulated to explore how CODEPINK is using a media innovation for social change: How is the social movement organization CODEPINK using media innovations to support more data-driven activist repertoires?

METHODS

The data collected for this study draws on 10 in-depth semi-structured interviews carried out during field research (Jan 1, 2018-October 1, 2018) using the online video application Zoom. This study is a subset of results from a larger year-long ethnographic study (2018) that included a digital ethnography, collection of Facebook and Twitter data, interviews, attendance at CODEPINK meetings, and protests. To address the research question the data focused on the interviews, which provided key qualitative data points. For this study purposive sampling was used, and the participants were selected based on the characteristics of the organization and their political activism. The main participants that were interviewed (9 women, 1 man) were the two founders of the CODEPINK organization, four campaign organizers, two communication officers, and one digital strategist. The interviews ranged from 45 minutes to 1.5 hours and focused on questions about the strategy of social networking sites, civic information, and operational practices. The interviews were semi-structured. The aim was to give all interviewees the same questions in almost the same order, but this was adapted as new information came to light (Bryman, 2012). The objective of this type of interviewing is that the questions are aggregated and that the responses have identical cues from each interviewee (Bryman, 2012). The questions were purposely formatted as open-ended questions, which allowed the respondents to openly discuss each ques- 
tion's topic and provide robust qualitative answers. An audio recorder was brought to the interviews and the online interviews were recorded to ensure accuracy in transcription. The data was anonymized to protect the participants' identities.

To analyze the interviews, a three-step content analysis was conducted using NVIVO 12. Reoccurring themes and patterns were extrapolated from coding for variables that reinforced the research question. The content analysis for this study was a cyclical practice that was divided into three main stages (Saldaña, 2009). During, the first round of coding I focused on the communication structures that were used to communicate to citizens. Within the first two rounds I developed codes for emails, text messages, social media engagements, protests, strategies, NationBuilder, and civic information. Further codes, dealt with three main issue frames related to understanding CODEPINK's use of ICT's: NationBuilder (CRM), Interestbased targeted emailing, and social matching. These three nodes provided qualitative data and supported insights into organizational practices that utilized data driven activist repertories. Moreover, the codes provided feedback on the current state of what activist groups are doing in order to combat modern-day activist problems using a media innovation.
RESULTS

The staff members of CODEPINK were each interviewed on a voluntary basis and were asked to comment to the best of their knowledge about a number of topics concerning organizational communication practices. The questions were geared towards understanding how CODEPINK is utilizing an ICT to support data driven activist repertories. The following sections will provide interview data and key results with regard to the research question.

NationBuilder (CRM)

CODEPINK is one of the few activist groups that is using a customer relationship management system called NationBuilder to manage their organizational contacts. The interview findings indicated that the use of a political CRM can assist an organization in automating the processes of relationship management and campaign support. Throughout the interviews members reiterated that NationBuilder allows them to manage their contacts, social networking sites, website, email, events, and fundraising more efficiently than in the past. The platform allows CODEDINK to use their own content to create and build a social infrastructure of data that gives feedback (social and email data) on the interests of their members. These data points have allowed the organization to target their messages more effectively, in- crease engagement, and understand the level of interest members have toward certain issues.

One member stated that CODEPINK utilized maybe 30 percent of NationBuilder's functionality (4 2018). CODEPINK, as the members described, utilized the functions of email targeting, social matching, text messaging, and donation recruitment. The human organizing aspects of the platform allowed the organization to practice methods of audience segmentation and specific targeting. These are data driven repertoires that spread civic information more efficiently. However, one CODEPINKER said that "we still don't use them (the tools) to the capacity that are available to us, but we're on a learning curve $(1,2018)$." The platform's high-level practices of targeting, while progressing the overall efficacy of messaging, was a theme throughout the interview data. Moreover, the data showed that CODEPINK had a rather large network of individuals, a backend system of about 400,000 members, consisting of contacts, email contacts, and social contacts on NationBuilder. Because of this the organization is able to communicate with contacts that were sourced from a variety of different publicly available or user-generated data sources and can therefore reach out to different niche interest groups.

NationBuilder collects social contacts from Facebook and Twitter, email, the organization's website, 
and manual self-reported contact data. The system then organizes all the data points into individual profiles that provide a summary of the digital actions that a person has taken. According to another member the organization utilizes, "the most basic level data that is publicly available" and "none of your data moves from entity to entity other than your public social data $(4,2018)$." Publicly available data points are a user's phone number, address, email, political affiliation, interests, and profession that are provided voluntarily by the user online and then integrated into the database along with data collected from social media. Collecting these data points helps inform the social strategies and relationship management of members for the organization to inform protest actions and relational marketing. Moreover, this process was described as a practice which allows the organization to disregard uninterested members who have not engaged with the organization.

If the organization wants to do a locally-targeted text message they can use data that they have collected about individuals either digitally or physically. One CODEPINK member said that, "we started using text messages for events...because all the data says that you are going to probably get 50 percent more from text messages" $(4,2018)$. This technique was also described as "fairly useful when we're on the ground and we're doing a location action to tell people in particular, let's say 25 miles, that we'd love to meet you" $(4,2018)$. For CODEPINKers, targeting members through geo-politics and text messaging, which seems to be a growing practice in the United States, really helps connect with individuals that have provided relevant data. Furthermore, the platform allows the organization to initiate fundraising through email and website data and keep track of how individuals have contributed to the organization. Using technology to expedite fundraising practices, helps overcome resource problems.

The triangulation of public data points about individuals has the potential to raise ethical concerns in relation to privacy protection. The convergence of personal data presented in an aggregated manner creates concerns for citizens, because they have little control over the information that is presented about themselves. However, during my exploration of CODEPINK I found that the information that the organization had on NationBuilder was informing strategic decisions based on large numbers of followers rather than individual followers. Moreover, the information that was gathered about any one individual was either voluntary information or information that could be found publicly through a search engine. According to a staff member, using these tools is effective because NationBuilder "understands human organizing" and "NationBuilder saw what activism really wanted, you are able to build a following" (1, 2018). Incorporating this media innovation tool into their communication practices, has, according to CODEPINKERs, proven to be effective with large followings on social networking sites and large email contact lists. In the following sections, I will provide insight into two particular NationBuilder functions that help organize members more effectively and email members with more data driven decisions. The digital strategist working with the organization during the interviews shared his strategy for the organization. Moreover, the campaign organizers shared their efficacy using NationBuilder to accomplish action repertoires.

\section{Social Matching}

Social matching is a function that refers to the process of a CRM triangulating digital information, which it collects from an individual's public social networking data (Facebook, Twitter, LinkedIn) and pairs with their email address. CODEPINK uses the functionality of social matching to connect emails to social accounts that already follow the organization's social pages. Organizationally, this feature benefits CODEPINK, because it digitally mediates relationships to more individuals than traditional organizing practices. CODEPINK says they are then better able to collect data points and react to user behavior and 
engagement aggregated to one profile. This ability to aggregate data helps provide insights for action repertoires to respond. A CODEPINKer said in "relation to participation that we can track engagement fairly accurately and that's connected to NationBuilder" (7, 2018). The triangulation of this data allows CODEPINK to organize interactions based on individual member interests.

If a profile is designated as being private, the system will not pull the user's social data to the platform. However, if public social information exists, the system will match even profile pictures to the NationBuilder platform. The social matching that occurs on the platform allows CODEPINK to more effectively plan a long arc strategy and organize people in terms of how they engage with CODEPINK. Throughout the interviews the reoccurring theme of changing the organizations narrative and having an influence to change problems, was specifically tied to understanding social data over time. This is a key element because it allows the organization to be proactive in their communication patterns with members and to lead conversations. Moreover, the social data could be segmented into individuals or "clusters of the people with those tags" and compared to the rest of the individuals on the contact list $(6,2018)$.

The process of social matching innovates and changes the way activist organizations can potentially encourage citizens to join in a social movement. Organizing individuals on the NationBuilder platform, with an aggregated set of social data and contact data, provides information to the organization more efficiently than traditional practices of manually entering information. Utilizing this software within the activist realm is an innovative use of social data and could potentially help activists achieve social change, because they are able to more easily utilize their relationships. A member of the organization described historical accounts of how she used to manage members on excel sheets and had difficulty targeting individuals to participate in data driven action repertoires $(6,2018)$. Moreover, one member during an interview said that they remembered going to protests with a clipboard in order gather member information, which is a much more cumbersome process in member management $(7,2018)$. With social matching the organization can still enter emails for members they meet in person, but also incorporate members they gained on social network sites to their email system and deliver civic information in a more targeted manner. In the following section I will discuss how that practice has aided communication problems by targeting the correct audiences, which in turn combats the organizational problem of sustained interest.
Interest-based targeted emailing

Email communication is quite often the only way CODEPINK can directly contact a member of their organization. For CODEPINK, emails serve as the main educational resource for civic and campaign information. Emails are structured so that they provide many opportunities for a member to engage with the organization's civic information and campaigns. CODEPINK utilizes data that is gathered from NationBuilder to better shape the relationships they have with individuals via email. In a full email alert, CODEPINK has significantly "fewer number of openrates than on a targeted niche campaign alert that is geared toward a cohort of individuals who are interested in certain civic information" $(4,2018)$. According to a CODEPINKer "you actually have a lot of different cohorts of people and you really need to think about them as that. And that the tags are much more representative of a cohort than just thinking I have a whole list" $(4,2018)$. The platform allows the organization to focus their emails via tags according to the same CODEPINKer, "instead of bombarding everyone with an email, we are able to focus more on what I think of as the rights apps to the right audiences at the right time" $(4,2018)$. The organization will create tags, which act as a characteristic about a certain individual. These tags create a taxonomy of different groups that are based on certain characteristics. The 
individuals who are tagged as having a certain characteristic can then be contacted with the premise that they had interacted with the organization in the past on that same civic information data point. Tags are created around a certain campaign topic, a petition that was signed, a social media post that was liked, or an action that an individual directly took with the organization, such as providing a donation or RSVP'ing to an event. A CODEPINKer said that "tags are critical to managing thriving campaigns and using email and data to develop more meaningful relationships. $(6,2018)$ " All members of the organization who do campaign planning have knowledge of how to utilize "different tags and the tag hierarchy within different campaigns" $(6,2018)$. During the interviews, it was described how top-level tags are campaigns and campaign issues, while lower-level tags are campaign tags/abbreviations, a sublevel of engagement, unique info, and the date.

When using Facebook events, a CODEPINKer said "that the NationBuilder action calendar has RSVP, so then we'll send that out to an email list through NationBuilder" $(6,2018)$. The NationBuilder system can also provide a multitude of different filters, which can organize individuals by whether they have opened up an email in the last three months, geographical locations, interests, and responses to emails. Utilizing and analyzing these emails and data points helps segment individuals into groups based on what an individual already feels politically connected to and helps the organization have higher open rates of engagement with their civic information.

\section{DISCUSSION}

The utilization of ICT's is aiding organizations that are operating in extensively saturated digital landscapes. This research advances social movement theory by addressing communication, social, and structural problems that are overcome by SMOs when using innovative media technologies. These support SMOs in engaging in more data-driven action repertories.

The ability to utilize contacts from social networking sites, email, and physical connections help organize digital communication, coordinate, and mobilize individuals who are helping combat modern-day activist problems. CODEPINK recognizes that there is a major opportunity to create Castells (2012) networked society of activists by using a political CRM. The utilization of a CRM combats the modern-day activist problems that Bimber, Flanagin, and Stohl (2012) discuss in their research. Examining the different CRM practices of a social movement organization also contributes to a new understanding of social movement problems that are being addressed by the digital technology industry.

CODEPINK's utilization of a political CRM to build relationships, through social matching, is an innovative function that addresses the need that Reddick and Anthopoulous (2014) describe of requiring multiple channels and interactions to get in contact with a member. Understanding social engagements with the organization can provide insight for organizations to create modern-day protests based on social incentives that are coordinated and not blind (Weber \& King, 2014). Using a political CRM strategically has provided the opportunity for audiences, that are identified through data-driven insights, to receive different civic information on digital channels more easily.

Due to the fact that most activist organizations are reactive, the ability to apply existing data on how individuals react to different campaigns is useful to adjusting their message to be more effective and targeted to their campaign messages in the future (Reile, 2019). This could influence whether an SMO can sustain interest from a member to engage in a social movement. CODEPINK utilizes NationBuilder for social matching by aggregating digital actions from social networking sites and then viewing those actions on a profile. Due to the ubiquitous nature of today's social networking site use, not understanding how your members are engaging with your organization online would negatively constrain strategic relationship management. Organizational 
efforts benefit greatly from these data points because they contribute to an understanding of how member content is creating that sense of belonging or identity that Bauermeister (2014) identified as being central to collective action. This reinforces the argument that citizens are the central data-point that influence how SMOs accomplish social change (Bauermeister, 2014). Moreover, analysing these actions helps to establish how many times a member has donated or been communicated with for a certain campaign or potential action.

Interest-based targeted emailing changes civic information practices by providing civic information that reflects the political campaigns and topics with which a user has previously engaged. With an increase of $19 \%$ of individuals consuming civic information on social networking sites, utilizing contacts from social networking sites allows CODEPINK to reach largerniche audiences via email that are segmented into cohorts (Verba, Brady, \& Schlozman, 2014). Karp's (2012) findings support this method of email targeting and that organizations can play a key role in political issues at pivotal moments. Interest-based email targeting was specifically discussed by interviewees as a strategy to re-engage members by more efficiently identifying topics of interest for action as Wells (2017) described. Emails have historically been the only source of connection that organizations were able to have with members. With emailing becoming more interest-based and targeted these organizaations are attempting to combat what Beck (1999) describes as the inability for organizations to develop relationships with individuals. More importantly, it points to a recognition by organizations that utilizing new media innovations could potentially help strengthen their data driven repertories and harness relationships to build micro-mobilizations for social change. Moreover, the use of these technologies addressed the need to understand the practices of activists who are combating communication challenges in the digital environment. It also begs further questions with regard to whether interest-based email practices take away the so called "ebb and flow" of interest that Zald and Ash (1966) describe as being a constant within social movements? Also, does it create a direct impact on the engagement of citizens and their belief that the organization is able to help create social change?

Concurrently, there are privacy concerns that surround the collection of public user data. However, the use of this data is a common business practice within the United States. From my study and the exploration of CODEPINK the information that was collected does fall under what Newlands, Lutz, Fieseler (2019) describe as volunteer data. The use of a CRM to manage connections by an activist group to gain traction in today's media landscape is an attempt to build member loyalty to a cause or campaign through data driven insights. More importantly it allows CODEPINK to more efficiently build social capital as Putnam (2000) described. By building social capital the organization can also build trust, which Alawadhi (2019) found to be difficult for SMOs. These practices potentially provide a link between customer management and civic engagement with political issues, where citizens are handled in the same way as a customer would be when buying a product. The product being engagement with a social issue, and the seller being the activist organization trying to get a citizen to join a social movement.

The ramifications of strategically using a political CRM, interest-based emailing, and social matching are an increased ability to target individuals to participate in social change actions. CODEPINK, is consistently exhibiting signs of growth on their social networking sites and building comprehensive cohorts of individuals that are based on interests recorded by their members' user-behavior. These actions are the framework for modern-day activist organizations who have much larger global networks from which they need to garner attention. Creating authentic audiences through these practices build reciprocity and community behavior that is essential to the success of any social movement organization (Rosenblum, 
2018). It could be argued that without the use of innovative media technologies and data driven repertories CODEPINK would not be able to compete effectively amongst modern social movement organizations.

\section{CONCLUSION}

CODEPINK is utilizing a CRM to create more data driven action repertories to organize and communicate with members and utilize digital connections more effectively. This research has implications for understanding how SMOs are incorporating media innovations into their practices to build relationships with members and achieve social change. It also contributes to an understanding of the role of data-driven repertoires in contemporary activism. The limitations of this research are that there is no first-hand platform data from NationBuilder and that the study focuses on one organization. Further research about other organizations who are using a CRM and creating more data-driven repertories is needed.

\section{Wiebke Reile}

University of Hawaili at Mānoa

wreile@hawaii.edu

\section{REFERENCES}

Alawadhi, S. (2019). A Proposed Model of Trust Factors for E-government Adoption and Civic Engagement. Proceedings of the 52nd Hawaii International Conference on System Sciences. doi:10.24251/hicss.2019.381

Al-Khouri, A. M. (2012). Customer Relationship Management: Proposed Framework from a Government Perspective Times. Journal of Management and Strategy, 3(4), 34-54. doi:10.5430/jms.v3n4p34

Anderson, J., \& Rainie, L. (2017). The Future of Truth and Misinformation Online. Retrieved January 24, 2019, from http://www.pewinternet.org/2017/10/19/thefuture-of-truth-and-misinformation-online/

Bauermeister, M. (2014). Social movement organizations in the local food movement: Linking social capital and movement support (Doctoral dissertation, Thesis / Dissertation ETD) (pp. 1-155). Iowa.

Beck, C. T. (1999). Quantitative measurement of caring. Journal of Advanced Nursing, 30(1), 24-32. doi:10.1046/j.1365-2648.1999.01045.x

Bimber, B., Flanagin, A., \& Stohl, C. (2012). Collective Action in Organizations. Communication Theory, 15. 365-388. doi:10.1093/ct/15.4.365

Brancati, D., \& Lucardi, A. (2018). Why democracy protests do not diffuse. Journal of Conflict Resolution, 63(10), 2354-2389. doi:10.1177/0022002718815957 Bryman, A. (2012). Social research methods. Oxford: Oxford University Press.
Castells, M. (2012). Networks of outrage and hope: Social movements in the Internet age. Cambridge, UK: Polity.

Chen, C. W., \& Gorski, P. C. (2015). Burnout in Social Justice and Human Rights Activists: Symptoms, Causes and Implications. Journal of Human Rights Practice, 7(3), 366-39o. doi:10.1093/jhuman/huvo11

Clark, J. A., \& Volpi, F. (2018). Activism in the Middle east and North Africa in times of upheaval: Social networks' actions and interactions. Social Movement Studies, 18(1), 1-16. doi:10.1080/14742837.2018.1538876

CODEPINK. (2019). Retrieved November 11, 2017, from http://www.codepink.org/

Das, S., \& Mishra, M. (2019). The Impact of Customer Relationship Management (CRM) Practices on Customer Satisfaction. Business Governance and Society, 43-54. doi:10.1007/978-3-319-94613-9_4

Cress, D. M., \& Snow, D. A. (2000). The Outcomes of Homeless Mobilization: The Influence of Organization, Disruption, Political Mediation, and Framing. American Journal of Sociology, 105(4), 1063-1104. doi:10.1086/210399

Das, S., \& Mishra, M. (2019). The Impact of Customer Relationship Management (CRM) Practices on Customer Satisfaction. Business Governance and Society, 43-54. doi:10.1007/978-3-319-94613-9_4 
Dumitrica, D., \& Felt, M. (2019). Mediated grassroots collective action: Negotiating barriers of digital activism. Information, Communication \& Society, 1-17. doi:10.1 080/1369118x.2019.1618891

Highfield, T. (2016). Social Media and Everyday Politics. Cambridge, UK: Polity Press.

Jenkins, J. C. (1983). Resource Mobilization Theory and the Study of Social Movements. Annual Review of Sociology, 9(1), 527-553. doi:10.1146/annurev. so.09.080183.002523

Jordan, M. \& Clement, S. (2018). Echoes of VIETNAM: Millions of Americans are taking to the streets. Washington Post. Retrieved November 17, 2019, from https://www.washingtonpost.com/news/national/ wp/2018/o4/o6/feature/in-reaction-to-trump-millions-of-americans-are-joining-protests-and-gettingpolitical/

Karpf, D. (2012). Social Science Research Methods in Internet Time. Information, Communication, and Society. 1. 639-661. doi: 10.1080/1369118X.2012.665468

Melucci, A., Keane, J., \& Mier, P. (1989). Nomads of the present: Social movements and individual needs in contemporary society. Philadelphia: Temple University Press.

Milan, S. (2013). Social movements and their technologies: Wiring social change. New York, NY: Palgrave Macmillan.
Newlands, G., Lutz, C., \& Fieseler, C. (2019). Trading on the Unknown: Scenarios for the Future Value of Data. The Law \& Ethics of Human Rights, 13(1), 97-114. doi:10.1515/lehr-2019-0004

Nvivo. (2019). Nivivo for Mac. Retrieved October 1, 2019, from http://www.qsinternational.com/product/ nvivo-mac

Pan, S., Tan, C., \& Lim, E. T. (2006). Customer relationship management (CRM) in e-government: A relational perspective. Decision Support Systems, 42(1), 237-250. doi:10.1016/j.dss.2004.12.001

Putnam, R. (200o). Social Capital: Measurement and Consequences. Retrieved December 14, 2016, from http://citeseerx.ist.psu.edu/viewdoc/download?doi=1 o.1.1.178.6284\&rep=rep1\&type=pdf

Reddick, C. (2010). Impact of citizen relationship management (CRM) on government: Evidence from U.S. local governments. Journal of E-Governance. Retrieved October 30, 2018, from https://dl.acm.org/citation. cfm?id=1839279

Reddick, C., \& Anthopoulos, L. (2014). Interactions with egovernment, new digital media and traditional channel choices: Citizen-initiated factors. Transforming Government: People, Process and Policy, 8(3), 398-419. doi:10.1108/tg-01-2014-0001

Saldaña, J. (2009). The Coding Manual for Qualitative Researchers. (1st ed.). Great Britain: Sage.
Rainie, L. \& Perrin, A. (2019). Key findings about AMERICANS' declining trust in government and each other. Retrieved November 17, 2019, from https://www. pewresearch.org/fact-tank/2019/o7/22/key-findingsabout-americans-declining-trust-in-government-andeach-other/

Reile, W. (2019). Activist Organizations and Strategic Utilization of Information and Communication Technologies: An Exploration of CODEPINK: Women for Peace (Doctoral dissertation, University of Hawaii Manoa, 2019) (pp. 1-184). ProQuest Dissertation Publishing. doi:13881430

Selander, L., \& Jarvenpaa, S. (2016). Digital Action Repertoires and Transforming a Social Movement Organization. Retrieved July 26, 2017, from http://misq.org/ digital-action-repertoires-and-transforming-a-socialmovement-organization.html

Tufekci, Z. (2017). Twitter and Tear Gas: The power and fragility of networked protest. New Haven: YALE University Press.

Tufekci, Z. (2017, January 27). Does a protest's size matter? New York Times. Retrieved November 17, 2019, from https://www.nytimes.com/2017/01/27/opinion/ does-a-protests-size-matter.html

Verba, S., Brady, H. E., \& Schlozman, K. L. (2002). Voice and equality: Civic voluntarism in American politics. Cambridge, MA: Harvard University Press. 
Weber, K., \& King, B. (2014). Social Movement Theory and Organization Studies. The Oxford Handbook of Sociology, Social Theory, and Organization Studies. doi:10.1093/oxfordhb/9780199671083.013.0021

Wellman, B., Quan Hasse, A., Witte, J., \& Hampton, K. (2001). Does the Internet increase, decrease, or supplement social capital? Social networks, participation, and community commitment. American Behavioral Scientist, 45(3), 436-455.

Wells, C. (2017). The civic organization and the digital citizen: Communicating engagement in a networked age. Oxford: Oxford University Press.

Zald, M. N., \& Ash, R. (1966). Social Movement Organizations: Growth, Decay and Change. Social Forces, 44(3), 327-341. doi:10.2307/2575833 